\title{
Papel da Vítima no Direito Português e no Direito Internacional
}

\author{
The Role of the Victim in Portuguese Criminal Law and \\ in International Law
}

MARIA JOÃO SIMÕES ESCUDEIRO

mjsescudeiro@gmail.com

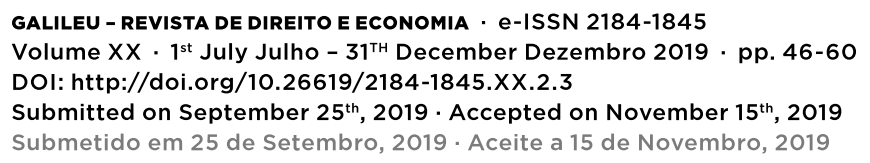

RESUMo A criação do Tribunal Penal Internacional é um dos feitos mais aguardados do século vinte.

As expetativas e anseios que recaem sobre o Tribunal são, de tal forma altos, que colocam a Comunidade Internacional de olhos postos nas suas decisões.

O Estatuto da Vítima está em vigor em Portugal e perante esta circunstância importa analisar o papel das vítimas nos Tribunais Penais Internacionais.

Analisaremos a evolução do papel das vítimas nos Tribunais Militares Internacionais de Nuremberga e do Extremo Oriente, passando pelos Tribunais Ad-Hoc da Ex-Jugoslávia e do Ruanda e culminando no Tribunal Penal Internacional.

A evolução nesta matéria é visível na prática destes tribunais, até porque a análise que se pretendemos fazer, é sobretudo, com base na jurisprudência destes Tribunais.

PALAVRASChaVES Vítima(direitos, papel, preponderância),Tribunais Penais Internacionais; Jurisprudência.

ABSTRACT The creation of the International Criminal Court is one of the most waited achievements of the twentieth century.

The expectations and desires that befall upon the Court are so high, that the eyes of the International Community are put in its decisions.

The Problems of Victims came into force in Portugal with this Law and we must examine the role of victims in International Criminal Tribunals. At this point, it's important that we analyze the evolution of the role of victims in International Military Tribunals of Nuremberg and Tokyo, through the Ad-Hoc Tribunals of the former Yugoslavia and Rwanda and culminating in the International Criminal Court. 
Developments in this field is visible in the practice of these courts, because the analysis that we intend to do, mainly based on the jurisprudence of these Courts.

KEY WORDS Victim (rights, role, prevalence), International Criminal Tribunals; Jurisprudence.

\section{Introdução}

Este artigo pretende analisar a problemática do papel da vítima no âmbito internacional, mas também, no âmbito do direito interno, por força de vigorar em Portugal o Estatuto da Vítima, que resultou da transposição de uma diretiva europeia'.

Consideramos que a evolução do Direito Internacional Penal e do Direito Processual Penal Internacional terá necessariamente reflexos no sistema jurídico português.

O tema que elegemos como objecto deste artigo reveste um especial interesse, em virtude de não se encontrar entre a doutrina portuguesa trabalhos de investigação que apresentem uma visão global detalhada sobre o papel da vítima nos procedimentos criminais internacionais, designadamente à luz do labor dos diversos tribunais penais internacionais e ao mesmo tempo concluindo da sua aproximação às famílias jurídicas da Civil e da Common Law. Assim, é também o nosso objectivo contribuir modestamente para preencher este vazio. Os Tribunais Penais Internacionais são instituições que, pela sua credibilidade e importância, tenderão, cada vez mais, a ser uma referência para as jurisdições nacionais. Os princípios orientadores da justiça internacional terão um reflexo, cada vez mais imediato, no desenvolvimento do direito interno dos Estados. Daí que acreditemos que este estudo contribua para uma nova abordagem a esta questão, o que nos permitirá observar o direito processual penal de outra forma com a vantagem da experiência internacional. Este conhecimento evita possíveis erros legislativos e antecipa problemas doutrinais e jurisprudenciais. Cremos que o desenvolvimento do direito processual penal português sairá beneficiado se o legislador e o julgador conhecerem os problemas e as soluções que, diariamente, vão surgindo nos Tribunais Penais Internacionais.

1 Transposição da Diretiva 2012/29/UE do Parlamento Europeu e do Conselho, de 25 de outubro de 2012, que estabelece normas relativas aos direitos, ao apoio e à proteção das vítimas da criminalidade e que substitui a Decisão-Quadro 2001/220/JAI do Conselho, de 15 de março de 2001. 


\section{Direito Português: Breves notas}

Desde o dia 4 de Setembro de 2015, entrou em vigor a Lei n. ${ }^{\circ}$ 130/2015, intitulada o Estatuto da Vítima. Esta lei resulta da transposição da Directiva 2012/29/EU do Parlamento Europeu e do Conselho, de 25 de Outubro de 2012. Este diploma estabelece normas relativas aos direitos, ao apoio e à proteção das vítimas de crimes.

O Direito Criminal Português, assim como, o Direito Penal Internacional tem o enfoque no agressor e nos direitos dos criminosos, daí que se verifique a necessidade de recentrar a vítima no processo criminal, tendo em consideração e esta se encontra muitas vezes arredada de todo o procedimento.

Com a entrada em vigor deste diploma e com a autonomização o conceito de vítima, inexistente até à data, procede-se à regulação dos seus direitos e consequentes apoios, partindo sempre da premissa que estamos perante um sujeito que se encontra por inerência fragilizado. Por outro lado, incluem-se na categoria de vítimas especialmente vulneráveis as vítimas de criminalidade violenta e criminalidade especialmente violenta, as crianças, os idosos ou aqueles que tenham especiais problemas de saúde que requeiram este estatuto.

Com a introdução deste diploma no ordenamento jurídico português, procedeu-se à enunciação expressa que a vítima que não se constituiu assistente, nem demandante civil, tem agora o direito de oferecer provas e ser ouvido. Mas mais, acrescentou-se o alargamento da possibilidade da vítima se constituir assistente após a leitura da sentença para interposição de recurso.

Esta Lei introduz ainda alterações aos Código de Processo Penal, onde se estabeleceu que vítima é não só a pessoa diretamente atingida pela prática de um crime, mas também aqueles que a rodeiam e que sofreram consequências com isso, designadamente o cônjuge, a pessoa com quem ela vive em união de facto, parentes em linha reta, irmãos ou pessoas a cargo.

Os princípios pressentes neste estatuto (doravante EV), são a igualdade (art. $3 .{ }^{\circ} \mathrm{do} \mathrm{EV}$ ), respeito e reconhecimento (art. $4 .^{\circ} \mathrm{do} \mathrm{EV}$ ), autonomia da vontade (art. 5. ${ }^{\circ} \mathrm{do} \mathrm{EV}$ ), confidencialidade (art. 6. ${ }^{\circ}$ do EV), consentimento (art. 7. ${ }^{\circ}$ do EV) e informação (art. 8. ${ }^{\circ}$ do EV). Desta forma, garantiu-se o sigilo de todas as informações prestadas pela vítima e prevê-se ainda o acesso da vítima aos cuidados de saúde, em função do tipo de crime. Além disso, há lugar ao reembolso das despesas efetuadas, existe o direito de proteção da vítima, devendo ser evitado o contacto direto com o arguido.

Previu-se igualmente a obrigação de prestar apoio psicossocial às vítimas vulneráveis e especialmente vulneráveis (arts. 20. ${ }^{\circ}$ e ss. do EV), bem como, a possibilidade de prestarem declarações para memória futura, conforme o art. $24 .^{\circ}$ do EV. 
No que respeita ao direito à informação, estabeleceu-se que a vítima deve ser informada sobre onde e como pode apresentar a denúncia, sobre os requisitos que regem o seu direito à indemnização, bem como o direito de ser informada quanto à sentença. Mais, terá também direito à informação sobre o estatuto do arguido, nomeadamente a sua libertação, revogação da decisão, ou mesmo, casos de alteração das medidas de coacção, de acordo com o art. $11 .^{\circ}$ previsto no EV.

Finalmente, determinou-se de uma forma muito inovadora que a vítima seja ouvida mesmo nos casos em que haja alteração da medida de coação. Para este efeito, a vítima deve ser sempre ouvida de forma "reservada", i. e., num gabinete dos órgãos de polícia criminal.

\section{Direito Internacional: Notas Introdutórias}

Os Juízes do Tribunal Penal Internacional (TPI) têm competência para resolver todas as questões processuais penais, mas também as questões relativas à reparação das vítimas - art. 75. ${ }^{\circ}$ do Estatuto de Roma. (Bassiouni, M. Cherif; 2005 Vol. 2; pp. 544-549.; Triffterer, Otto; 2008, pp. 1399-1412; Cassese, A. and Others; 2002, 2002; pp. 1399-1416) O TPI define que serão estabelecidos os princípios aplicáveis às formas de reparação das vítimas, nomeadamente, a restituição, a indemnização e a reabilitação. O termo «princípios» atribui aos Juízes discricionariedade que permite a flexibilidade necessária para determinar as consequências dos crimes cometidos sob a jurisdição do TPI. (Triffterer, Otto; 2008; pp. 1402-1405).

O Estatuto de Roma é conhecido pelas suas previsões inovadoras, designadamente, no que diz respeito ao tratamento das vítimas. Esta novidade atribui às vítimas o direito de participarem no processo. (Lee, Roy; 2001; pp. 235-255) Brianne N. Macgonigle afirma que o papel e os direitos das vítimas diferem consoante se enquadrem no sistema adversarial ou inquisitorial. Embora mesmo entre os sistemas inquisitoriais se encontrem diferenças, todos concedem uma posição participativa às vítimas, designadamente através da participação das partes civis. Nos sistemas inquisitoriais, as vítimas têm um papel processual em que são a fonte da informação para o Tribunal, enquanto testemunhas, mas também como alguém que sofreu os danos, ou seja, enquanto vítima. O papel mais importante das vítimas neste sistema é o direito de pedir uma indemnização pelos danos sofridos, diretamente no decorrer do procedimento criminal. (Lee, Roy; 2001; pp. 235-255) Às vítimas é permitido apresentar os seus argumentos e preocupações, assim como questionar as testemunhas e recorrer contra a absolvição do arguido. ${ }^{2}$

2 Idem. Segundo este autor "este procedimento é vantajoso para as vítimas se o arguido for condenado, porque não terão de provar a culpa do arguido pelos danos sofridos num processo civil autónomo. Por outro lado, quando um arguido é absolvido, as jurisdições não são uniformes quanto à questão de saber se as vítimas podem ou 
Diferentemente, os sistemas adversariais não admitem a participação das vítimas nos procedimentos a não ser como testemunhas, visto que não são partes formais no processo. (Macgonigle, Brianne N.; Artigo 2009; p. 5); (Jouet, Mugambi; Artigo 2007; p. 4) Nos sistemas adversarial, as vítimas podem participar como testemunhas, ficando sujeitas às questões da defesa. Os sistemas da Common Law confiam nos resultados que se obtém da argumentação e contra-argumentação entre as partes. Estes sistemas equilibraram o papel limitado atribuído às vítimas defendendo os seus interesses de outras formas. Por exemplo, no sistema inglês os Juízes têm autoridade para ordenar que o arguido pague indemnizações às vítimas, mesmo que estas não o tenham solicitado. (Jouet, Mugambi; Artigo 2007; p. 4) Para além da indemnização através do procedimento criminal, os sistemas da Common Law permitem que as vítimas obtenham compensação para os danos sofridos nos tribunais cíveis. Por exemplo, nos EUA as vítimas podem recorrer aos tribunais cíveis para obterem as suas indemnizações, até porque estes tribunais são menos exigentes com a prova dos que os tribunais criminais. (Jouet, Mugambi; Artigo 2007; p. 4)

A evolução apresentada pelo TPI apresenta-nos uma característica dos sistemas da Civil Law permitindo uma reparação dos danos sofridos pela vítima, ao contrário do que sucedia nos Tribunais Militares ou nos Tribunais Ad Hoc em que se seguiu um procedimento principalmente adversarial, sendo a participação das vítimas "resumida" ao seu papel enquanto testemunhas. O objetivo desta novidade é o facto de se acreditar que as vítimas têm um interesse próprio nos procedimentos internacionais que não pode ser salvaguardado através da representação de outra parte. (McGoldrick, Dominic and Others; 2004; p. 320). Os procedimentos internacionais podem claramente beneficiar com a participação das vítimas que têm conhecimentos na primeira pessoa os atos alegadamente praticados pelo arguido. ( Jouet, Mugambi; Artigo 2007; p. 4)

$\mathrm{O}$ art. $75 .^{\circ}$ do Estatuto de Roma vem suprimir uma séria lacuna dos Estatutos do TPIJ, do TPIR e dos Tribunais Militares de Nuremberga e de Tóquio, que não definiam a questão da reparação das vítimas. (Triffterer, Otto; 2008; p. 1411)

Nos Tribunais Ad Hoc, os interesses das vítimas foram muitas vezes negligenciados, porque estes Tribunais só tiveram em conta o seu papel enquanto testemunhas. Durante os procedimentos, as vítimas só eram ouvidas como testemunhas da acusação ou da defesa. Neste sentido, as vítimas não poderiam ser compensadas pelo sofrimento vivenciado. Esta situação era deixada para os tribunais nacionais ou para outra instituição competente.

não iniciar um processo civil, com o obejtivo de obterem uma indemnização. Por exemplo, a lei francesa proíbe que os Juízes dos processos civis tomem decisões contrárias às decisões dos Juízes criminais, mas a legislação norueguesa já permite que as vítimas possam intentar um processo civil autónomo, mesmo que que o arguido tenha sido absolvido." 
(McGoldrick, Dominic and Others;2004; p. 320) Face ao exposto, o TPIJ e o TPIR caracterizam as vítimas de duas formas: as vítimas não podem ser parte nos procedimentos criminais e não podem obter indemnizações pelos danos sofridos. A primeira prerrogativa é exercida pelo Procurador, que representa os interesses da comunidade internacional (incluindo as vítimas). A segunda recai nas jurisdições dos tribunais nacionais. (Cassese, A. and Others; 2002; pp. 1387-1388)

Neste contexto, é importante analisar como é que se podem conciliar os deveres do Procurador, os direitos dos arguidos e a legitimidade das vítimas. (Cassese, A. and Others; 2002; pp. 1389) A justiça dos processos inclui o respeito pelos direitos processuais do Procurador, da defesa e das vítimas como se encontram garantidos no Estatuto de Roma. (Tochilousky, Vladimir; 2008; p. 520)

Face ao exposto, parece-nos que os Juízes do TPI terão competência para conhecer todas as questões, inclusive as de natureza civil.

Esta novidade é, a nosso ver, um salto qualitativo gigantesco do TPI. Este reconhecimento é algo que a nós nos pareceria inevitável e hoje a sua concretização é uma realidade em progresso. Esta característica dos sistemas inquisitórios permite um reconhecimento do sofrimento da vítima, o que é fundamental para a paz internacional nos dias de hoje. Este é um passo muito importante para a realização da justiça internacional.

\section{O Papel das Vítimas no Tribunal Militar Internacional e no Tribunal Militar Internacional para o Extremo Oriente}

A questão sobre o papel das vítimas não se coloca no âmbito destes Tribunais. Aqui o mais importante foi dar o primeiro passo para se julgarem internacionalmente os grandes criminosos. Daí que os procedimentos não englobassem um papel fundamental para as vítimas, porque os Procuradores procuravam representar a justiça internacional.

\section{O Papel das Vítimas no Tribunal Penal Internacional para a Ex-Jugoslávia (TPIJ) e no Tribunal Penal Internacional para o Ruanda (TPIR)}

Nestes Tribunais atribuiu-se ao Procurador a tarefa de representar as vítimas em todas as fases do processo, deixando para os Tribunais nacionais a função de atribuir as indemnizações ${ }^{3}$.

3 Regra 106 do Regulamento Processual de ambos os Tribunais. 
As vítimas não têm uma participação ativa no processo, não lhes são reconhecidos quaisquer direitos especiais de participação no julgamento ou de se poderem dirigir diretamente ao Tribunal. Isto significa, que não têm direito a dirigir-se ao Tribunal para se manifestar sobre a concessão da liberdade provisória do arguido, nem para se pronunciar sobre factos relevantes para a pena a atribuir ao arguido. (Boas, Gideon and Others; 2011; p. 309)

Todavia, este sistema ignora o facto de que a vítima que pessoalmente participe no processo pode desempenhar um papel fundamental na descoberta da verdade. Mas, mais do que isto, a possibilidade de uma vítima participar no processo e obter uma indemnização pode ajudar a recuperar a sua dignidade, contribuindo para a restauração da paz nos territórios envolvidos.(Cassese, A. and Others; 2002; p. 1389)

Estes Tribunais focaram-se sobretudo na proteção das vítimas. Os Estatutos e os seus Regulamentos Processuais não preveem o direito de as vítimas participarem no processo.

Durante o julgamento, as vítimas só podem ser ouvidas como testemunhas da acusação ou da defesa e estão sujeitas a cumprir uma série de requisitos, designadamente, não podem recusar-se a testemunhar, sob pena de serem penalizadas pelo Tribunal; têm de fazer o juramento de só dizerem a verdade, tendo em conta que se existir perjúrio podem ser processadas; não podem exigir a presença de um advogado; não têm direito a ter acesso às provas apresentadas por qualquer das partes; não podem solicitar ser informadas do andamento do processo, mesmo quando lhes diga diretamente respeito e, por último, não podem estar presentes quando outras testemunhas estejam a prestar depoimento.(Cassese, A. and Others; 2002; p. 1390-1391)

Neste Tribunais as vítimas são chamadas a testemunhar, principalmente, se as suas declarações corroborarem as provas apresentadas pela acusação. (Commentary Marc Groenhuijsen and Anne-Marie Brouwer. In Klip, Andre and Sluiter, Göran; 2010 ICC; p. 273)

O fundamento utilizado para justificar esta situação, menos participativa das vítimas nos Tribunais Ad Hoc, era o facto de se considerar que a atuação dos Procuradores seria suficiente para garantir a proteção dos interesses da comunidade internacional, incluindo aqui os direitos das vítimas.(Commentary Marc Groenhuijsen and Anne-Marie Brouwer. In Klip, Andre and Sluiter, Göran; 2010 ICC; p. 273)

Não obstante o regime apresentado, os Estatutos do TPIJ e do TPIR prevêem formas de reparação dos danos sofridos pelas vítimas. O art. $24 .^{\circ}, \mathrm{n} .{ }^{\circ} 3$, do Estatuto do TPIJ, e o art. $23^{\circ}, \mathrm{n}^{\circ}$ 3, do Estatuto do TPIR, preveem a restituição das propriedades que o arguido tenha adquirido ilegalmente. Perante este preceito, sempre que o Tribunal considere que a apropriação indevida da propriedade está relacionado com o crime pelo qual o arguido foi condenado, deve ordenar a sua restituição. 
Esta experiência demonstrou que "nem sempre os interesses da acusação coincidem com os interesses das vítimas" (Commentary Marc Groenhuijsen and Anne-Marie Brouwer. In Klip, Andre and Sluiter, Göran; 2010 ICC; p. 273) e por conseguinte no TPI verificou-se a necessidade de proteger os seus interesses, como veremos no ponto seguinte.

Este sistema adotado pelos magistrados do TPIJ e do TPIR respeita o sistema adversarial, no qual o papel das vítimas é o de testemunhas de alguma das partes e, em princípio, não podem reclamar pela reparação dos danos sofridos. (Cassese, A. and Others; 2002; pp. 1390-1391)

\section{O Papel das Vítimas no Tribunal Penal Internacional (TPI)}

Ao contrário do que sucede nos Tribunais Ad Hoc, no TPI as vítimas têm direitos de participação nos procedimentos com o objetivo de prosseguirem os seus interesses pessoais.

De acordo com o art. $19 .^{\circ}$, n. ${ }^{\circ}$ 3, do Estatuto de Roma, as vítimas podem apresentar as suas observações ao Tribunal sobre as questões de jurisdição e admissibilidade.

Para além disso, o TPI admite a participação das vítimas nos procedimentos, permitindo que as vítimas sejam representadas por um advogado e que tenham uma voz ativa durante o julgamento. (Jouet, Mugambi; Artigo 2007; p. 1)

As vítimas dos crimes que se encontram sob a jurisdição do TPI têm algumas necessidades que pretendem ver compensadas: “(1) Receber uma compensação pelos danos sofridos; (2) Verificar que o criminoso foi punido; (3) Ter um local onde possam falar e ser ouvidas; Conhecer a verdade sobre as questões políticas que provocaram os danos que lhes foram infligidos." (Jouet, Mugambi; Artigo 2007; p. 1 e 2)

A análise a fazer vai no sentido de conhecer as previsões do Estatuto de Roma sobre o papel das vítimas, nomeadamente, sobre as suas possíveis intervenções durante as diferentes fases do processo.

Esta situação não tem precedentes na justiça internacional e por conseguinte o TPI irá enfrentar os desafios inerentes à participação das vítimas nos procedimentos criminais. Todavia, o TPI poderá recorrer à prática das jurisdições nacionais para articular da melhor forma a participação das vítimas. (Commentary Marc Groenhuijsen and Anne Marie de Brouwer. In Klip, Andre and Sluiter, Göran; 2010 ICC; p. 274)

"O TPI deve garantir que a participação de um grande número de vítimas nos procedimentos, não afetará a realização de um julgamento justo, imparcial e célere". (Commentary Marc Groenhuijsen and Anne Marie de Brouwer. In Klip, Andre and Sluiter, Göran; 2010 ICC; p. 274)

Nos procedimentos do TPI, as vítimas têm direito a tomar parte nos processos, a serem informadas sobre os desenvolvimentos dos processos e a obterem a reparação dos seus pre- 
juízos. A definição de vítima encontra-se na Regra 85 do Regulamento Processual do TPI. O Tribunal de Recurso do TPI teve ocasião de definir quem pode ser qualificado como vítima para poder intervir nos procedimentos, bem como, determinar a abrangência da sua participação nos processos, quer na fase de investigação, quer na fase de julgamento. O Tribunal de Recurso decidiu, por unanimidade, que um indivíduo pode ser considerado uma vítima conforme a Regra 85, se tiver sofrido um dano direto ou de forma indireta. ${ }^{4}$ Ficou também decidido que os danos sofridos têm de estar relacionados com os crimes de que o arguido é acusado. Só satisfeitos estes pressupostos é que as vítimas poderão participar no processo. (Karim, Khan and Others; 2010; p. 543)

A interpretação do art. $68 .^{\circ}$, n. $^{\circ} 3$, do Estatuto de Roma ${ }^{5}$ é aplicável à fase de investigação, mas é também consistente e logo aplicável a todas as fases do processo. (Tochilousky, Vladimir; 2008; p. 519. McGoldrick, Dominic and Others; 2004; p. 322) Contudo, a participação das vítimas está sujeita a alguma discricionariedade judicial. Os Juízes determinarão não só se os interesses pessoais das vítimas são afetados, mas também se a fase é a apropriada à intervenção das vítimas. (McGoldrick, Dominic and Others; 2004; p. 323) No caso Lubanga, cumprindo a previsão do art. $68^{\circ}$, n. $^{\circ} 3$, do Estatuto de Roma, as vítimas participaram ativamente no caso e solicitaram a apresentação de prova, questionaram as testemunhas e avançaram com uma série de observações orais e escritas com a permissão do Tribunal e com a colaboração dos seus representantes legais. Foram autorizadas a participar nos procedimentos 129 vítimas (34 mulheres e 95 homens). Três dos depoimentos das vítimas não foram valorados pelo Tribunal por falta de credibilidade e foi-lhes retirada a autorização anteriormente concedida pelo Tribunal de participarem nos procedimentos. ${ }^{6}$

O Estatuto de Roma garante às vítimas uma voz independente e um papel nos procedimentos. (Tochilousky, Vladimir; 2008; p. 519) ${ }^{7}$

Todavia, as modalidades de participação das vítimas nos procedimentos devem garantir que não são prejudiciais ou inconsistentes com os direitos da defesa. Nestas circunstâncias, o Tribunal pode nomear um advogado ad hoc para representar os interesses da defesa. ${ }^{8}$

\footnotetext{
4 Prosecutor v. Thomas Lubanga Dyilo; ICC-01/04-01/06, 11 July 2008, §§ 38-39.

$5 \mathrm{O}$ art. $68 .^{\circ}, \mathrm{n} .^{\circ}$ 3, do Estatuto de Roma refere que: «Se os interesses pessoais das vítimas forem afetados, o Tribunal permitir-lhes-á que expressem as suas opiniões e preocupações em fase processual que entenda apropriada e por forma a não prejudicar os direitos do arguido nem a ser incompatível com estes ou com a realização de um julgamento equitativo e imparcial».

6 Prosecutor v. Thomas Lubanga Dyilo, Case No. ICC-01/04-01/06, 14 March 2012, pp. 3, 4 e 5.

7 Situation in the Democratic Republic of the Congo, Case No. ICC-01/04, 17 January 2006; §§ 50 e 51. In Tochilovsky, Vladimir; 2008; p. 519.

8 Idem, § 70. In Tochilovsky, Vladimir; 2008; p. 521.
} 
Quando o Juízo de Instrução tomar oficiosamente medidas, conforme o art. $56 .^{\circ}, \mathrm{n} .^{\circ} 3$, al. a), e $57^{\circ}$, n. ${ }^{\circ}$, al. c), do Estatuto de Roma, deve decidir se as vítimas devem participar no processo, tendo em conta os seus interesses pessoais. ${ }^{9}$

O desafio é conciliar os direitos dos arguidos e das vítimas, direitos que são, só por si, conflituantes. No intuito de concretizar este propósito, Mugambi Jouet apresenta duas hipóteses: a realização de uma interpretação adequada das normas sobre a participação das vítimas nos procedimentos ou a sua alteração. A primeira situação a definir é a interpretação do art. $68 .^{\circ}$, n. ${ }^{\circ} 3$, no sentido de saber quando é que as vítimas devem integrar os procedimentos. Assim, as vítimas não devem integrar os procedimentos até que esteja provado que são vítimas. (Jouet, Mugambi; Artigo 2007; p. 12) Segundo este autor, a solução será interpretar esta norma da forma mais adequada ao desenvolvimento dos procedimentos, porque a possível alteração da norma seria algo quase impossível de realizar, visto que isso significaria ainda mais garantias para os arguidos. Perante este facto, a oposição a uma possível alteração inviabilizaria qualquer tentativa nesse sentido.

No que diz respeito a saber se as vítimas podem participar na fase de recurso, é mais uma vez importante conhecer os seus interesses pessoais. As vítimas poderiam recorrer das decisões que autorizassem ou recusassem a libertação da pessoa objeto de inquérito ou de procedimento criminal, de acordo com o art. 82. ${ }^{\circ}$, n. ${ }^{\circ}$ 1, al. b) do Estatuto de Roma. Para que o Tribunal de Recurso admita a participação das vítimas, é necessário que elas façam uma declaração sobre se e como é que os seus interesses pessoais são afetados pelo recurso, bem como porque é que a participação das vítimas é apropriada. ${ }^{10}$ Esta questão é polémica porque Claude Jorda e Jérôme de Hemptinne referem que as vítimas não têm direito ao recurso contra o arguido. Permitam-nos discordar, porque consideramos que as vítimas devem ter direito a recorrer em conjunto com a acusação contra o arguido se os seus interesses pessoais forem afetados e se isso contribuir para a justiça internacional.

Para além disto, compete ao Tribunal decidir se as vítimas têm ou não direito à indemnização. Para o fazer, deve possuir certas informações, incluindo a descrição do prejuízo, da perda ou do dano, bem como conhecer o local e a data do incidente. Portanto, todos os documentos relativos a esta questão devem ser anexados, incluindo os nomes e as moradas das testemunhas. (Cassese, A. and Others; 2002; pp. 1406-1407) O Tribunal de 1. ${ }^{a}$ Instância do TPI permitiu que as vítimas participem através de representação legal que elucide as provas apresentadas. (Cassese, A. and Others; 2002; pp. 1407-1408) Esta reparação às vítimas deve ser feita pelo indivíduo condenado, e apenas se lhe for impossível ou impraticável se deverá

9 Idem, § 73. In Tochilovsky, Vladimir; 2008; p. 521.

10 Prosecutor v. Thomas Lubanga Dyilo, Case No. ICC-01/04-01/06, 13 February 2007, §§ 38 a 45. In Tochilovsky, Vladimir; 2008; p. 522. 
recorrer ao Fundo a favor das vítimas, previsto no art. $79 .^{\circ}$ do Estatuto de Roma. (Cassese, A. and Others; 2002; pp. 1407-1408)

Apesar do reconhecimento de todos estes direitos, as vítimas não têm os mesmos direitos das outras partes. Não devem participar nas investigações realizadas pelo Procurador, não têm acesso às provas apresentadas pelas partes nem podem chamar testemunhas a depor.

O Tribunal tem ainda muito trabalho para fazer, apesar de todas as garantias referidas. A primeira questão que deve ser esclarecida é o papel das vítimas durante a fase de investigação, considerando que esta questão não é clara, nem decorre do Estatuto ou dos Regulamentos Processuais. Por outro lado, o Regulamento Processual ainda não definiu formas para que as vítimas possam estar presentes nos procedimentos. As Regras Processuais também não definem se uma das partes pode chamar uma vítima a intervir nos procedimentos como testemunha. Em ordem a salvaguardar os direitos do arguido, é necessário garantir que uma vítima não seja, ao mesmo tempo, uma testemunha. É preciso equilibrar o direito do arguido a ter um julgamento célere com os direitos das vítimas. É também importante dividir o processo em duas fases, uma para a acusação e defesa e outra para as vítimas. (Cassese, A. and Others; 2002; pp. 1409-1417)

A 7 de agosto de 2012, no caso Thomas Lubanga Dyilo"11, o Tribunal de 1. ${ }^{a}$ Instância decidiu estabelecer os princípios aplicáveis às formas de reparação, tais como a restituição, a indemnização ou a reabilitação que decorrem do art. $75 .{ }^{\circ}, \mathrm{n} .{ }^{\circ} 1$, do Estatuto de Roma. Pela primeira vez, o Tribunal reconheceu que o Estatuto de Roma e o seu Regulamento Processual apresentam um sistema de reparação que, crescentemente, reconhece a necessidade de a justiça criminal internacional ir para além do que é a justiça punitiva. ${ }^{12}$ Caminhamos para uma justiça mais inclusiva, em que se encoraja a participação das vítimas e se reconhece a necessidade de reparação dos direitos das vítimas. Neste caso, o Tribunal concluiu que «a reparação das vítimas deveria minimizar o sofrimento infligido e as consequências que daí advieram, bem como, impedir violações futuras e contribuir para a efetiva reintegração das crianças soldado». ${ }^{13}$ Para além disso, a reparação deve ser feita de forma flexível, por forma a garantir «a maior reparação possível das violações dos direitos das vítimas.»14

Com fundamento na Regra 85 do Regulamento Processual, o Tribunal considerou que a reparação deve ser para as vítimas que sofreram danos de forma direta, mas também para

\footnotetext{
11 Prosecutor v Thomas Lubanga Dyilo; Case No. ICC-01/04-01/06; Decision Trial Chamber, 7 August 2012.

12 Idem, § 177.

13 Idem, § 179.

14 Idem, § 180 .
} 
as que sofreram de forma indireta, incluindo os familiares das vítimas. ${ }^{15}$ Neste caso, o Tribunal definiu que as indemnizações deveriam ser garantidas pelo Fundo sob fiscalização do Tribunal. Importa ainda referir dois outros critérios presentes nesta Regra, que é o facto de os crimes em causa estarem sujeitos à jurisdição do TPI e também o nexo de causalidade entre o crime praticado e o dano sofrido. ${ }^{16}$

No caso Thomas Lubanga Dyilo, o Tribunal, na fase de investigação, reconheceu seis pessoas como vítimas. Contudo, a 29 de junho de 2006, o Juízo de Instrução rejeitou a participação dessas pessoas como vítimas, porque os crimes que elas sofreram não coincidem com os crimes de que o arguido é acusado. ${ }^{17}$ Um mês depois, a 28 de julho de 2006, o Tribunal reconsiderou e reconheceu como vítimas três das pessoas anteriormente rejeitadas, porque eram parentes de crianças que tinham sido obrigadas a alistar-se na milícia alegadamente chefiada por Thomas Lubanga Dyilo. ${ }^{18-19}$

Uma das decisões mais controversas do Tribunal foi a permissão concedida a algumas vítimas de poderem participar nos procedimentos sob anonimato. ${ }^{20} \mathrm{O}$ Tribunal enfrentou o dilema de ter de harmonizar os direitos do arguido com a necessidade de proteger as vítimas da intimidação, ameaça ou possíveis danos. ${ }^{21} \mathrm{O}$ Tribunal não permitiu que fossem conhecidas as identidades das vítimas, conforme a Regra 87. Para cumprir esta exigência todas as informações que pudessem conduzir à identificação das vítimas foram retiradas dos documentos revelados à defesa.

A defesa protestou veementemente contra esta situação afirmando que deveria conhecer a identidade quem pretendia receber indemnizações. Para fundamentar esta pretensão utilizou vários argumentos: (1) as medidas de proteção eram medidas extraordinárias, que eram injustificadas naquelas circunstâncias; (2) esse facto levou à formulação de acusações anónimas impróprias; (3) as informações nos documentos eram muito vagas, porque omitiam a idade das vítimas no momento da prática do alegado crime; (4) uma defesa não pode ser bem organizada se não conhecer todos os elementos referentes à identidade das vítimas; (5) a informação omitida pode ser prova ilibatória, por exemplo não existir nexo de causalidade com os crimes em acusação; (6) o direito do arguido a ser julgado de forma célere pode ser posto em causa por a defesa ter de prolongar a sua análise devido às infor-

15 Idem, § 194.

16 Prosecutor v. Thomas Lubanga Dyilo, Case No. ICC-01/04-01/06, 17 January 2006; §§ 77-94.

17 Prosecutor v. Thomas Lubanga Dyilo, Case No. ICC-01/04-01/06, 29 June 2006; pp. 8-9.

18 Prosecutor v. Thomas Lubanga Dyilo, Case No. ICC-01/04-01/06, 28 July 2006. Vd.

19 Vd. Commentary Marc Groenhuijsen and Anne Marie de Brouwer. In Klip, Andre and Sluiter, Göran; 2010 ICC; p. 276.

20 Vd. Prosecutor v. Thomas Lubanga Dyilo; ICC-01/04-01/06-437, Decision Trial Chamber I, 19 September 2006 e Decision 20 September 2006

21 Prosecutor v. Thomas Lubanga Dyilo; ICC-01/04-01/06-437, Decision Trial Chamber I, 15 September 2006 , p. 8. 
mações omitidas; (7) a acusação beneficiar de informações que a defesa desconhece viola o direito à igualdade de armas e a um julgamento justo; e (8) a regra 87 não prevê que a identidade das vítimas não seja revelada à defesa, mas sim à comunicação social, ao público e a agências de informações, porque as medidas de segurança devem estar subordinadas aos direitos dos arguidos. ${ }^{22}$

O Tribunal sustentou que o privilégio do anonimato acarreta um limite à participação das vítimas, porque estas não poderão acrescentar factos ou provas à acusação formulada contra o arguido. ${ }^{23}$

Esta intervenção das vítimas nos procedimentos está relacionada com a prática dos sistemas da Civil Law.

Em síntese, o sistema adoptado pelo TPI é híbrido, mas sobressaem características dos sistemas da Civil Law. Todavia, apresentadas as lacunas que ainda estão por clarificar, tendemos a concluir que ainda não estamos perante um sistema totalmente fiel aos sistemas da Civil Law, sendo por isso, suigeneris.

\section{Conclusão}

O papel das vítimas no direito português, bem como, no direito internacional denota uma evolução muito significativa nos Tribunais Penais Internacionais. Inicialmente, no TMI e no TMIEO a possibilidade de reparação dos danos sofridos pelas vítimas era uma questão que nem se colocava e, hoje, temos o TPI a decidir sobre estas matérias. Entre este espaço temporal, os Tribunais Ad Hoc consideravam que as vítimas se encontravam representadas pelo Procurador.

Os desenvolvimentos desta questão aproximam-no dos sistemas da Civil Law, sendo as vítimas partes nos processos e tendo direito à reparação dos danos sofridos. Esta situação é diferente da que sucede nos sistemas da Common Law em que as vítimas são apenas testemunhas nos processos.

Sintetizando, a participação das vítimas do TPI é uma realidade, tendo adquirido preponderância nos procedimentos criminais. Embora, o sistema adotado pelo TPI se aproxime da prática dos sistemas da Civil Law, consideramos que estamos perante um sistema jurídico-criminal único.

Hoje, em Portugal, esperamos "caminhar a passos largos" para as posições reconhecidas e respeitadas internacionalmente.

22 Prosecutor v. Thomas Lubanga Dyilo; ICC-01/04-01/06-437, Decision Trial Chamber I, 4 September 2006, pp. 7-10.

23 Prosecutor v. Thomas Lubanga Dyilo; ICC-01/04-01/06-437, Decision Trial Chamber I, 22 September 2006 , p. 7. 


\section{BIBLIOGRAFIA}

\section{Bassiouni, M. Cherif}

2005 The Legislative History of the International Criminal Court: Article-by-Article Evolution of the Statute; Vol. 2. Ardsley, New York; Transnational Publishers, Inc.

Boas, Gideon; Bischoff, James L.; Reid, Natalie L. and Taylor III, B. Don

2011 International Criminal Law Practitioner Library Series, Volume III. Cambridge University Press Cassese, Antonio; Gaeta, Paola and Jones, Jonh R. W. D.:

2002 The Rome Statute of the International Criminal Court: A Commentary: Materials, Volume I and II. New York, Oxford University Press.

\section{Jouet, Mugambi}

2007 Reconciling the Conflicting Rights of Victims and Defendants at the Internacional Criminal Court. In Saint Louis University Public Law Review, 249

Lee, Roy $S$.

2001 The International Criminal Court: The Making of the Rome Statute: Issues, Negotiations and Results. The Netherlands, Kluwer Law International

\section{Macgonigle, Brianne $\mathbf{N}$.}

2009 Bridging the Divides in International Criminal Proceedings: an Examination into the Victim Participation Endeavor of the International Criminal Court. Copyright (c) 2009 Florida Journal of Interntional Law 93.

Mcgoldrick, Dominic; Rowe, Peter and Donnelly, Eric

2004 The Permanent International Criminal Court: Legal and Policy Issues. Oxford, Hart Publishing. Khan, Karim A. A.; Buismen, Caroline and Gosnell, Christopher

2010 Principles of Evidence in International Criminal Justice. Oxford University Press.

\section{Klip, André and Sluiter, Göran}

2010 Annotated Leading Cases of International Criminal Tribunals. The International Criminal Tribunals, Intersentia, André Klip and Göran Sluiter Eds.

2010 Annotated Leading Cases of International Criminal Tribunals. The International Criminal Tribunal for Rwanda 2006-2007. Intersentia, André Klip and Göran Sluiter Eds.

\section{Tochilovsky, Vladimir}

2008 Jurisprudence of the International Criminal Courts and the European Court of Human Rights. Leiden/Boston, Martinus Nijhoff Publishers.

\section{Triffterer, Otto}

2008 Commentary on the Rome Statute of the International Criminal Court, Observers' Notes, Article by Article. Munich Germany. Nomos Verlagsgesellschaft Baden-Baden.

\section{JURISPRUDÊNCIA}

Thomas Lubanga Dyilo (ICC-01/04-01/06)

Judgment on the Appeal of Prosecutor and the Defence Against Trial Chamber I's Decision on Victim's Participation of 18 January 2008; Majority Opinion, 11 July 2008

Prosecution's Application to Lift the Stay of Proceedings, 11 July 2008

Judgment Hearing, 14 March 2012

Decision Establishing the Principles and Procedures to be Applied to Reparations, 7 August 2012

Decision on the Applications for Participation in the Proceedings Submitted by VPRS 1 to VPRS 6 in the Case the Prosecutor v. Thomas Lubanga Dyilo, 29 June 2006 
Decision on the Applications for Participation in the Proceedings of a/0001/06, a/0002/06 and a/0003/06 in the case of the Prosecutor v. Thomas Lubanga Dyilo and of the investigation in the Democratic Republic of the Congo, 28 July 2006

Defence Observations Relative to the Proceedings and Manner of Participation of Victims a/00o1/06 to a/0003/06, 4 September 2006

Second Decision on the Prosecution Requests and Amended Requests for Redactions under Rule 81, 20 September 2006

Decision on the Arrangements for Participation of Victims a/0001/06, a/0002/06 and a/0003/06 at the Confirmation Hearing, 22 September 2006 - p. 229 